TITLE:

\title{
Sexual attractiveness shared by both sexes mediates same-sex sexual behaviour in the parasitoid wasp Telenomus triptus
}

\section{AUTHOR(S):}

Todoroki, Yusuke; Mochizuki, Ko; Numata, Hideharu

\section{CITATION:}

Todoroki, Yusuke ... [et al]. Sexual attractiveness shared by both sexes mediates same-sex sexual behaviour in the parasitoid wasp Telenomus triptus. Physiological Entomology 2015, 40(3): 239-246

\section{ISSUE DATE:}

2015-09

URL:

http://hdl.handle.net/2433/202101

\section{RIGHT:}

This is the peer reviewed version of the following article: Todoroki, Y., Mochizuki, K. and Numata, H. (2015), Sexual attractiveness shared by both sexes mediates same-sex sexual behaviour in the parasitoid wasp Telenomus triptus. Physiological Entomology, 40: 239-246, which has been published in final form at

http://dx.doi.org/10.1111/phen.12107. This article may be used for non-commercial purposes in accordance with Wiley Terms and Conditions for Self-Archiving.; The full-text file will be made open to the public on $1 \mathrm{JUL} 2016$ in accordance with publisher's 'Terms and Conditions for Self-Archiving'; This is not the published version. Please cite only the published version.; この論文は出版社版でありません。引用の際には出版社版をご確認ご利用ください。 
Sexual attractiveness shared by both sexes mediates same-sex sexual behaviour in the parasitoid wasp Telenomus triptus

YUSUKE TODOROKI, KO MOCHIZUKI* and HIDEHARU NUMATA

Graduate School of Science, Kyoto University, Sakyo, Kyoto, Japan

Correspondence: Hideharu Numata, Graduate School of Science, Kyoto University, Sakyo, Kyoto 606-8502, Japan. Tel.: +81 075753 4073; e-mail: numata@ethol.zool.kyoto-u.ac.jp

* Present address: Center for Ecological Research, Kyoto University, 2-509-3 Hirano, Otsu, Shiga 520-2113, Japan 
Abstract. The mating behaviour of a quasi-gregarious egg parasitoid, Telenomus triptus Nixon, which exploits egg masses of a stink bug, Piezodorus hybneri (Gmelin), is examined in the laboratory. In this species, male adults that emerge earlier stay at the natal egg mass and mate with subsequently emerging females. In the present study, a male adult that encounters the emergence of another male always waits for it to egress, and then mounts the newly emerging male. To examine why males of $T$. triptus show same-sex sexual behaviour, male adults were presented with a parasitized host egg mass or a freshly killed wasp. Male adults remained at host egg masses from which only male wasp(s) had emerged. In addition, male adults attempted to copulate with freshly killed young male wasps. It is suggested that newly emerging male wasps are targets of same-sex sexual behaviour because they possess cues for male sexual behaviour that are similar to the cues of females. Both sex and age of freshly killed wasps affected the frequency of the sexual behaviour of male adults: females were more attractive than males, but their attractiveness declined with age. When the mating opportunity is restricted to the natal egg mass, the costs of failing to notice newly emerging female adults should be extremely high. Therefore, males are forced not to discriminate the sex, resulting in same-sex sexual behaviour.

Key words. Homosexual behaviour, Hymenoptera, local mate competition, Platygastridae. 


\section{Introduction}

Same-sex sexual behaviour, i.e., homosexual behaviour, is prevalent among insect orders (Scharf \& Martin, 2013). This behaviour does not result in direct progeny production and there is empirical evidence that same-sex interactions impose costs on engaging individuals in seed beetles Callosobruchus maculatus and Acanthoscelides obtectus, and in a carrion fly, Prochyliza xanthostoma (Maklakov \& Bonduriansky, 2009; Stojković et al., 2010). One of the explanations for the same-sex sexual behaviour is misidentification caused by incomplete sex recognition (Bailey \& Zuk, 2009). For example, in a water bug, Palmacorixa nana, and a beetle, Diaprepes abbreviates, in which females are larger than males on average, it is suggested that males tend to mount conspecifics of large body size (Aiken, 1981; Harari et al., 2000). In moths Zeiraphera diniana and Corcyra cephalonica, and a stink bug, Piezodorus hybneri (Gmelin), a substantial proportion of males attempt copulation with other males when they are excited by a cue for locating potential mates, such as a volatile sex pheromone (Benz, 1973; Hall et al., 1987; Leal et al., 1998). Some parasitic wasps also show same-sex sexual behaviour (e.g. Robacker et al., 1976; Antolin \& Strand, 1992; Al-Wahaibi et al., 2005; Steiner et al., 2005; Benelli et al., 2012), which evidently imposes costs on engaging males (Ruther \& Steiner, 2008; Benelli et al., 2013). In parasitic wasps, newly emerging males are also often attractive to other males (Quicke, 1997). Steiner et al. (2005) suggested that immature males of Lariophagus distinguendus (Pteromalidae) receive courtship behaviour from other males because they possess chemical compounds similar to those of females.

Many wasp species in the family Platygastridae are solitary endoparasitoids that exploit host egg masses (Austin et al., 2005), and are called quasi-gregarious parasitoids (van den Assem et al., 1980). In this group, female wasps are inseminated immediately upon emergence, presumably by males that emerge earlier from the same host egg mass (Wilson, 
1961; Waage, 1982). Therefore, in species that parasitize small-sized host egg masses, a high degree of local mate competition occurs, leading to female-biased sex ratio (Hamilton, 1967; Waage, 1982). The oviposition behaviour of female wasps allocating male and female eggs in a particular sequence provides only a minimum number of male offspring to fertilize all daughters within each host patch (Hardy 1992), i.e. each host egg mass in quasi-gregarious parasitoids (e.g. Hokyo et al., 1966; Waage, 1982; Welzen \& Waage, 1987; Strand, 1988; Bayram et al., 2004). In such situations, a male wasp seldom encounters other males, and therefore suffers little cost from potential same-sex sexual behaviour. Moreover, females of such species show reduced sexual receptivity with age (e.g. Schwartz \& Gerling, 1974; Loch \& Walter, 1999; Salerno et al., 2012) and females of many parasitic wasps mate only once (Quicke, 1997). The restriction of mating opportunity to the natal site forces males to stay at their emergence sites and increases the costs of failing to notice emerging female wasps. Thus, males of such species may be expected to attempt copulation without any strict sex recognition. Indeed, males of Trissolcus basalis (Hymenoptera: Platygastridae) occasionally mount and attempt copulation with another male during a series of wasp emergence from a parasitized host egg mass both in the laboratory and in the field (Wilson, 1961, Loch \& Walter 2002). However, the immediate mechanisms that cause same-sex sexual behaviour have not been examined in Platygastridae.

Telenomus triptus Nixon (Hymenoptera: Platygastridae) is a quasi-gregarious egg parasitoid and one of the major natural enemies of stink bugs Piezodorus hybneri and Eysarcoris guttiger (Heteroptera: Pentatomidae) in soybean fields (Higuchi, 1993, 1994b; Higuchi \& Suzuki, 1996; Hirose et al., 1996). Females of T. triptus parasitize egg masses of $P$. hybneri, consisting of 2-47 eggs, and of E. guttiger, consisting of 2-17 eggs (Higuchi, 1994b, Hirose et al., 1996). This species shows female-biased sex ratios in emerging adults from collected host eggs, in trapped adults from soybean fields, and in adults raised in the 
laboratory (Higuchi, 1993; Hirose et al., 1996, Icuma \& Hirose, 1996; Higuchi \& Suzuki, 1996). A female T. triptus exploits all eggs of a host egg mass and tends to allocate a male egg within the early part of an oviposition bout (Higuchi \& Suzuki, 1996), ensuring at least one male in each egg mass (the latter of which can be of various sizes). In this species, a male adult emerges earlier than females from an egg mass (Icuma \& Hirose, 1996). In preliminary observations for the present study, an emerging male stayed at the natal egg mass and subsequently mated with his female siblings upon their emergence. When we gave an egg mass of $P$. hybneri to a mated female $T$. triptus, usually a few male and approximately 20 female wasps emerge from it. Only male wasps emerge from an egg mass parasitized by a virgin female due to haplodiploid sex determination. During successive emergence of male adults from such an egg mass, male wasps often stayed at the natal egg mass, waiting for the emergence of other males, attempting to copulate with them.

The aim of the present study is to examine the mechanisms of same-sex sexual behaviour in T. triptus. First, in order to quantify male sexual behaviour toward other newly emerging males, successive emergence of male adults from two host eggs is observed. Then, to examine what causes this behaviour of male wasps, a parasitized host egg mass is presented to a male wasp. Moreover, to clarify the stimulus for male copulation attempts, and to determine whether only newly emerging individuals receive copulation attempts, freshly killed female or male wasps of different ages are presented to a male wasp.

\section{Materials and methods}

Insects

Egg masses of $P$. hybneri were placed in a soybean field in Kameoka, Kyoto, Japan $\left(35^{\circ} 01^{\prime} \mathrm{N}\right.$, $135^{\circ} 35^{\prime} \mathrm{E}$ ) in September 2012 and 2013, and collected after 4 days. Naturally laid egg masses 
of P. hybneri were collected in the same field in September 2014. Adults of T. triptus emerging from these host eggs and their progeny were reared successively on egg masses of $P$. hybneri. All experiments were performed under a photocycle of $16 \mathrm{~h}$ light and $8 \mathrm{~h}$ darkness, at $25 \pm 1.0{ }^{\circ} \mathrm{C}$ and $95 \% \mathrm{RH}$, unless otherwise stated. Adult wasps were kept individually in cotton-plugged glass tubes (10 $\mathrm{mm}$ dia., $75 \mathrm{~mm}$ length) containing honey diluted with water and solidified by agar until used for experiments. Adults of $P$. hybneri were collected from the same soybean field between August and October in 2012, 2013 and 2014, or from a grassplot of white clover, Trifolium repens, in Kashima, Kumamoto, Japan (3244’N, $130^{\circ} 46^{\prime} \mathrm{E}$ ) in June 2013 . These adults and their progeny were reared on soybean and peanuts at the same temperature and photoperiod (which prevents adult diapause; Higuchi, 1994a), to obtain egg masses for parasitization by T. triptus.

Adult wasps were allowed to mate upon emergence from parasitized host egg masses that were kept separately in glass tubes. Both male and female wasps usually emerged from a host egg mass parasitized by a mated female (egg mass with both-sex wasps). To obtain virgin females and males, parasitized egg masses were separated into single eggs using forceps and a razor and kept individually until adult emergence. Only male wasps emerged from an egg mass parasitized by a virgin female (egg mass with only male wasps) due to haplodiploid sex determination.

\section{Definition of male sexual behaviours}

In preliminary observations of successive emergence of wasps from a parasitized egg mass, the following sexual behaviours of male adults were noted (see Supporting information, Appendix S1). An egg mass was usually possessed by a dominant male which patrolled it and chased intruders. While a female wasp gnawed her host egg shell at emergence, the dominant male often stopped at the egg and held forward and slightly vibrated his antennae (watching 
posture). When the anterior part of the body of the female wasp was exposed out of the host egg, the male started to climb her, bending his antennae in an arcing form and vibrating them vigorously (mount). After the body of the female wasp was completely exposed, the male extruded his genitalia (aedeagus extrusion) and curled his metasoma until successful copulation. The time when the body of a wasp was completely exposed as it exits from the host egg shell was defined as the emergence of the wasp. During successive emergence of male adults from egg masses with only male wasps, male adults often showed "watching posture" and "aedeagus extrusion" upon the emergence of other males (see Supporting information, Appendix S2).

\section{Male behaviour toward an emerging male}

The sexual behaviour of a male adult toward a newly emerging male was observed in the laboratory. Because the developmental time of male T. triptus is approximately 11 days at $25{ }^{\circ} \mathrm{C}$ in P. hybneri eggs (Icuma \& Hirose, 1995), the following observation device was prepared 10 days after oviposition. Two eggs separated from an egg mass with only male wasps were glued vertically side by side with an interval of approximately $0.5 \mathrm{~mm}$ on a piece of paper towel. A cylindrical hole (12 mm dia., $25 \mathrm{~mm}$ depth) of a rack for microcentrifuge tubes was used as an observation chamber. The hole was stuffed with slightly moistened cotton at a depth of approximately $5 \mathrm{~mm}$ to maintain the humidity. A piece of paper towel with the glued-on eggs was placed on the top of the cotton in each of 6 or 9 adjacent holes of the rack. These holes were covered with translucent acrylic sheet and placed under a video camera (HDR-SR12, Sony, Tokyo, Japan). The behaviour of emerging males was recorded by the video camera for $4 \mathrm{~h}$ after lights on. This procedure was replicated on 3 different days.

Male wasps were referred to as the first and second males based on emergence order. The emergence of the second males was successfully recorded in 10 holes of the rack. The 
occurrence and duration of "watching posture" and "mount" were examined in the first male for $60 \mathrm{~s}$ before and after the emergence of the second male.

\section{Male behaviour toward a parasitized host egg mass}

An egg mass with both-sex wasps or with only male wasps was presented to a male wasp.

The day when the first wasp emerged from a host egg mass was designated as day 0 , and egg masses were used on day -2 , day -1 , day 0 , day +1 , and day +2 . Each egg mass was introduced into a glass tube (10 $\mathrm{mm}$ dia., $75 \mathrm{~mm}$ length) with a male wasp whose behaviour was observed for 15 min under a stereoscopic microscope (S8AP0, Leica Microsystems, Welzlar, Germany) at $25^{\circ} \mathrm{C}$. The staying time was defined as the duration from the touching of the male's foreleg(s) to the egg mass until the detachment of all legs from the egg mass. In each trial, the maximum staying time and the occurrence of "watching posture" were recorded. Virgin male wasps were used for experiments 0-13 days after emergence. The egg masses used for the experiment consisted of 5-35 eggs and were checked daily to record the day of emergence of the first wasp.

The trials in which the male wasp touched the egg mass were used for the analysis. For each type of egg mass (with both-sex wasps or with only male wasps), the staying time was compared among days from the emergence of the first wasp by the Kruskal-Wallis test, followed by the Steel-Dwass test for multiple comparisons. For each day from the emergence, the staying time was compared between the two types of egg masses by the Mann-Whitney $U$-test. For each type of egg mass, the occurrence of "watching posture" was compared among days from the emergence of the first wasp by Tukey-type multiple comparisons for proportions (Zar, 2010). For each day from the emergence, the occurrence of "watching posture" was compared between the two types of egg masses by Fisher's exact test. Analyses were carried out in the R statistical package, version 3.0.3 (R Core Team 2014). 
Male behaviour toward a freshly killed conspecific

A freshly killed, young or old, female or male wasp was presented to a male wasp. Wasps that emerged from separated host eggs during the first half of the light period were killed on the day of emergence or 3 days after that. They were frozen at $-35^{\circ} \mathrm{C}$ for $10 \mathrm{~min}$ and then kept at $25^{\circ} \mathrm{C}$ for 10 min until the experiment. A freshly killed wasp was introduced into a glass tube with a male wasp whose behaviour was video-recorded for 20 min using a digital camera (EX-F1, Casio, Tokyo, Japan) installed on a stereoscopic microscope (S8AP0, Leica Microsystems). Virgin male wasps that emerged from separated eggs were used for the experiment $0-3$ days after emergence.

The trials in which the male wasp touched the freshly killed wasp were used for the analysis. The occurrence of "aedeagus extrusion" by male wasps was recorded. The proportion of males that showed "aedeagus extrusion" was examined by Tukey-type multiple comparisons for proportions (Zar, 2010).

\section{Results}

Male behaviour toward an emerging male

During successive emergence of two male wasps, the male adult that emerged earlier (first male) showed sexual behaviour upon subsequent emergence of the other male (second male). In most cases, the first male showed watching posture before the emergence of the second male (Fig. 1). During watching posture, most of the first males touched with their foreleg(s) the host egg shell from which the second male was emerging. In addition, all the first males repeatedly mounted the second male, and all the second males were mounted before their emergence (complete exposure of their bodies) from the host eggs. The first males usually rotated on the second males until facing the same direction as the second males immediately 
before mounting them. All the first males curled their metasoma within $120 \mathrm{~s}$ of the emergence of the second male. Therefore, a male wasp always waited for subsequent emergence of another male and attempted copulation with a newly emerging male, in the absence of any female wasps. Although the same-sex sexual behaviours were frequent under these conditions, a single bout of the behaviour took only a short time. The duration of watching posture and mount was less than $30 \mathrm{~s}(3-25 \mathrm{~s})$ and less than $60 \mathrm{~s}(3-46 \mathrm{~s})$, respectively.

\section{Male behaviour toward a parasitized host egg mass}

To examine what causes male wasps to stay at the natal egg masses, a host egg mass different from the natal one was presented to a male wasp. Male wasps stayed significantly longer on egg masses from which adult wasp(s) had already emerged than on egg masses from which adult wasp(s) had not emerged yet, regardless of whether the egg mass contained wasps of both sexes (Fig. 2A) or only male wasps (Fig. 2B). The staying time of male wasps on egg masses was not significantly different between the types of egg masses (with wasps of both sexes or with only male wasps) on each day (Mann-Whitney $U$-test, $P>0.05$ ). Therefore, male wasps stay at their natal egg mass not simply due to being immobile after their emergence, but in response to some cue on egg masses from which adult wasp(s) have already emerged. Moreover, the cue exists on egg masses with only male wasps as well as on those with waspsof both sexes.

Male wasps also showed watching posture on parasitized host egg masses.

Significantly higher proportions of male wasps showed watching posture on egg masses from which adult wasp(s) had already emerged than on egg masses from which adult wasp(s) had not emerged yet, whether the egg mass contained wasps of both sexes (Fig. 3A) or only male wasps (Fig. 3B). The proportions of male wasps that showed watching posture on an egg 
mass were not significantly different between the types of egg masses (with wasps of both sexes or with only male wasps) on any of the days examined (Fisher's exact test, $P>0.5$ ). Therefore, the egg mass from which adult wasp(s) had already emerged induced watching posture by male wasps irrespective of whether the egg mass contained female wasp(s) or not.

In most egg masses with only male wasps, all of the eggs were empty on days +1 and +2 , where the day when the first wasp emerged from a host egg mass was designated as day 0 . The fact that male wasps also stayed and showed watching posture on these egg masses indicates that the cue for staying and showing watching posture by males should be in the empty host egg.

\section{Male behaviour toward a freshly killed conspecific}

To examine whether only newly emerging individuals possess the cue that induces copulation attempt by male wasps, a freshly killed wasp was presented to a male wasp. Male wasps showed sexual behaviour toward these freshly killed conspecifics also. Both the sex (female or male) and age (0-day-old or 3-day-old) of the freshly killed wasps affected the responses of male wasps (Fig. 4). Freshly killed female wasps of both ages elicited aedeagus extrusion in significantly higher proportions of male wasps than did freshly killed male wasps. Thus, female wasps were more attractive to males than male wasps. A significantly lower proportion of male wasps showed aedeagus extrusion to freshly killed 3-day-old female wasps than to 0 -day-old ones. Thus, 3-day-old females were less attractive to males than 0-day-old female wasps. Four of 15 male wasps showed aedeagus extrusion to freshly killed young male wasps; this proportion was not significantly different from that to 3-day-old female wasps. Thus, 0-day-old male wasps also elicited sexual behaviour in other male wasps. In 19 of 22 cases, male wasps showed aedeagus extrusion within $120 \mathrm{~s}$ after they touched freshly killed conspecifics. 


\section{Discussion}

In the present study, male adults of $T$. triptus frequently showed same-sex sexual behaviour when a male wasp encountered an emerging male; the former waited for the latter and mounted it. A male wasp stayed on a parasitized egg mass whether it contained female wasp(s) or not. Moreover, a male wasp attempted copulation with a freshly killed 0-day-old male. From these results, it is suggested that newly emerging male wasps receive same-sex sexual behaviours because they possess the same cue(s) for male sexual behaviour as females do. Newly emerging male parasitoid wasps have been reported to possess a female sex pheromone in Itoplectis conquisitor (Robacker et al., 1976) and Lariophagus distinguendus (Steiner et al., 2005). In T. triptus, freshly killed 3-day-old female wasps were less attractive to male wasps than 0-day-old ones. A similar decline of female attractiveness has been shown in other platygastrid wasps, Telonomus remus (Schwartz \& Gerling, 1974) and Trissolcus brochymenae (Salerno et al., 2012), in which involvement of a female sex pheromone has been shown. Thus it is probable that newly emerging adults of male and female T. triptus possess the same chemical compound(s) that triggers male sexual behaviour, and its amount declines with age.

Male wasps stayed on empty host eggs from which wasps had emerged. Males of other parasitoid wasps are also attracted to an empty cocoon or empty host mummy from which a female wasp has emerged (Tagawa \& Kitano, 1981; Schwörer et al., 1999). In the present study, male $T$. triptus stayed even at an empty egg mass from which only male wasps had emerged. Tagawa \& Kitano (1981) showed that males of a braconid wasp, Cotesia glomerata (formerly Apanteles glomeratus), are attracted to an empty cocoon of the same species but not an ether-washed one, suggesting the involvement of a chemical compound in attraction to cocoons. In T. triptus, one possible explanation of male attraction to an empty 
host egg is that a sex pheromone shared by adults of both sexes contaminated the empty host egg. Another possibility is that the pupal exuvia or meconium or both possess the cue for staying by male adults.

Although male wasps mounted newly emerging males, a lower proportion of male wasps attempted copulation with a freshly killed male wasp than with a female. Male wasps may have lower attractiveness for other males. Although we cannot deny the possibility of presence of a female specific pheromone, it is more probable that the amount of an attractant in male wasps is lower than that in females or the attractant diminishes with age more rapidly (within $8 \mathrm{~h}$ ) in males than in females. In L. distinguendus, male wasps have been suggested to metabolise their sex pheromone that is similar to female wasps after emergence (Steiner et al., 2005). In the fruit fly Drosophila melanogaster, immature males elicit quantitatively the same courtship behaviour of other males as do virgin females (McRobert \& Tompkins, 1983). However, they start to lose sexual attractiveness between 3 and $4 \mathrm{~h}$ after eclosion (Curcillo \& Tompkins, 1986). Mature males synthesize cis-vaccenyl acetate, which inhibits courtship behaviour of males, whereas immature males possess an insufficient amount of it (Jallon, 1984).

Although quasi-gregarious parasitoid wasps presumably mate with siblings at the natal patch, some field studies showed that male wasps also disperse and some female wasps disperse as virgins, suggesting that off-patch mating also occurs (Myint \& Walter, 1990; Nadel \& Luck, 1992; Loch \& Walter, 2002). In T. triptus, male wasps were caught by sticky traps in the field (Higuchi, 1993), and the longevity of males was approximately $85 \%$ as long as that of females at $25^{\circ} \mathrm{C}$ in the laboratory (Y. Todoroki \& H. Numata, unpublished observations), suggesting the possibility of male dispersal from the natal patch. Therefore, off-patch mating may also occur in T. triptus. The present results show that male wasps discriminate between the egg masses from which wasps have emerged and those from which 
no wasps have emerged yet, and stay at the former egg masses. This ability would enable dispersing male wasps to locate emergence sites of female wasps and subsequently mate with them. Males of Nasonia vitripennis can discriminate parasitized host puparia from unparasitized ones and are strongly attracted to puparia from which wasps have emerged (King et al., 1969). Males of Spalangia cameroni are also attracted to parasitized host pupae more strongly than to unparasitized pupae (Myint \& Walter, 1990). Although the current experiments have not compared the responses of males to parasitized and unparasitized hosts in T. triptus, the males stayed at egg masses from which only male wasps had emerged. Because male wasps emerge earlier than females and each parasitized host egg mass contains at least one male wasp (Higuchi \& Suzuki, 1996; Icuma \& Hirose, 1996), an empty host egg from which a male wasp has emerged in an egg mass indicates that female wasps will soon emerge from the egg mass. Therefore, it seems advantageous for male wasps to stay at an empty host egg from which a male wasp has emerged. The present finding that female wasps lose the cues for male sexual behaviour with age indicates a difficulty in mating with a female wasp that has dispersed from the natal patch. The actual proportion of outbreeding in the field remains to be examined.

The same-sex sexual behaviour in male T. triptus may impose costs on male wasps engaging in this behaviour. However, each parasitized host egg mass contains only a minimum number of male wasps (Higuchi \& Suzuki, 1996). Under natural conditions, therefore, emerging males encounter other male wasps much less frequently than females. Furthermore, the present results show that a single bout of sexual behaviour of a male wasp with another newly emerging male wasp requires less than 1 min. Thus, male wasps have scarce opportunities to show same-sex sexual behaviour, and suffer only a slight cost for it in terms of time and energy. Thus, in T. triptus, as Scharf \& Martin (2013) point out for various insects and arachnids, the cost of failing to notice newly emerging female wasps may 
outweigh the cost of same-sex sexual behaviour.

In parasitic Hymenoptera, newly emerging males are often attractive to other males (Quicke, 1997). Theoretical studies predict that in haplodiploid species, especially panmictic ones, a female would not gain fitness from investing in mating: without insemination a female can produce male offspring, and the fitness gain from producing a son equals that from producing a daughter when the sex ratio of the population is 1:1 (Iwasa, 1981; Godfray, 1990). Because males must mate to gain fitness, by contrast, males rather than females of haplodiploid species have a general tendency to bear the costs of searching for mates (Godfray \& Cook, 1997). In quasi-gregarious parasitoids, female wasps are presumably inseminated immediately upon emergence (Wilson, 1961; Waage, 1982), and therefore they need not search for mates. Even after female wasps disperse from the natal patch as virgins, they can produce male offspring, which might locate other emergence sites and mate there. Thus, female wasps might not invest in producing a sex-specific pheromone that facilitates pre-copulatory sex recognition, and male wasps respond sexually to a cue shared by both sexes (Godfray \& Cook, 1997), resulting in same-sex sexual behaviour in males.

\section{Supporting Information}

Additional Supporting Information may be found in the online version of this article at the publisher's web-site:

Appendix S1 Male sexual behaviours toward an emerging female in Telonomus triptus.

Appendix S2 Male sexual behaviours toward an emerging male in Telenomus triptus.

\section{Acknowledgements}


We thank Masaho Haikata for cooperation in the field collection in Kameoka, and Nobuo Mizutani for providing adults of Piezodorus hybneri from Kashima. Our thanks are also due to Yoshito Suzuki for critical reading of the manuscript and Elizabeth Nakajima for linguistic corrections.

\section{References}

Aiken, R.B. (1981) The relationship between body-weight and homosexual mounting in Palmacorixa nana Walley (Heteroptera, Corixidae). Florida Entomologist, 64, $267-271$

Al-Wahaibi, A.K., Owen, A.K. \& Morse, J.G. (2005) Description and behavioural biology of two Ufens species (Hymenoptera: Trichogrammatidae), egg parasitoids of Homalodisca species (Hemiptera: Cicadellidae) in southern California. Bulletin of Entomological Research, 95, 275-288.

Antolin, M.F. \& Strand, M.R. (1992) Mating system of Bracon hebetor (Hymenoptera, Braconidae). Ecological Entomology, 17, 1-7.

Austin, A.D., Johnson, N.F. \& Dowton, M. (2005) Systematics, evolution, and biology of scelionid and platygastrid wasps. Annual Review of Entomology, 50, 553-582.

Bailey, N.W. \& Zuk, M. (2009) Same-sex sexual behavior and evolution. Trends in Ecology \& Evolution, 24, 439-446.

Bayram, A., Salerno, G., Conti, E. et al. (2004) Sex allocation in Telenomus busseolae, a solitary parasitoid of concealed eggs: the influence of host patch size. Entomologia Experimentalis et Applicata, 111, 141-149. 
Benelli, G., Bonsignori, G., Stefanini, C. \& Canale, A. (2012) Courtship and mating behaviour in the fruit fly parasitoid Psyttalia concolor (Szepligeti) (Hymenoptera: Braconidae): the role of wing fanning. Journal of Pest Science, 85, 55-63.

Benelli, G., Gennari, G., Francini, A. \& Canale, A. (2013) Longevity costs of same-sex interactions: first evidence from a parasitic wasp. Invertebrate Biology, 132, $156-162$.

Benz, G. (1973) Role of sex pheromone, and its insignificance for heterosexual and homosexual behavior of larch bud moth. Experientia, 29, 553-554.

Curcillo, P.G. \& Tompkins, L. (1986) The ontogeny of sex appeal in Drosophila melanogaster males. Behavior Genetics, 17, 81-86.

Godfray, H.C.J. (1990) The causes and consequences of constrained sex allocation in haplodiploid animals. Journal of Evolutionary Biology, 3, 3-17.

Godfray, H.C.J. \& Cook, J.M. (1997) Mating systems of parasitoid wasps. The Evolution of Mating Systems in Insects and Arachnids, (ed. by J.C. Choe and B.J. Crespi), pp 211-225. Cambridge University Press, Cambridge, U.K.

Hall, D.R., Cork, A., Lester, R. et al. (1987) Sex-pheromones of rice moth, Corcyra cephalonica Stainton .2. Identification and role of female pheromone. Journal of Chemical Ecology, 13, 1575-1589.

Hamilton, W.D. (1967) Extraordinary sex ratios. Science, 156, 477-488.

Harari, A.R., Brockmann, H.J. \& Landolt, P.J. (2000) Intrasexual mounting in the beetle Diaprepes abbreviatus (L.). Proceedings of the Royal Society B-Biological Sciences, 267, 2071-2079.

Hardy, I.C.W. (1992) Non-binomial sex allocation and brood sex-ratio variances in the parasitoid Hymenoptera. Oikos, 65, 143-158. 
Higuchi, H. (1993) Seasonal prevalence of egg parasitoids attacking Piezodorus hybneri (Heteroptera, Pentatomidae) on soybeans. Applied Entomology and Zoology, 28, 347-352.

Higuchi, H. (1994a) Photoperiodic induction of diapause, hibernation and voltinism in Piezodorus hybneri (Heteroptera, Pentatomidae). Applied Entomology and Zoology, 29, 585-592.

Higuchi, H. (1994b) Seasonal prevalence and mortality factors of eggs of Piezodorus hybneri Gmelin (Heteroptera, Pentatomidae) in a soybean field. Japanese Journal of Applied Entomology and Zoology, 38, 17-21.

Higuchi, H. \& Suzuki Y (1996) Host handling behavior of the egg parasitoid Telenomus triptus to the egg mass of the stink bug Piezodorus hybneri. Entomologia Experimentalis et Applicata, 80, 475-479.

Hirose Y, Takasu K, Takagi M (1996) Egg parasitoids of phytophagous bugs in soybean: Mobile natural enemies as naturally occurring biological control agents of mobile pests. Biological Control, 7, 84-94.

Hokyo, N., Kiritani, K., Nakasuji, F. \& Shiga, M. (1966) Comparative biology of the two Scelionid egg parasites of Nezara viridula L. (Hemiptera: Pentatomidae). Applied Entomology and Zoology, 1, 94-102.

Icuma, I.M. \& Hirose, Y. (1996) Effects of temperature on development and survival of the egg parasitoid Telenomus triptus Nixon (Hymenoptera: Scelionidae) in two pentatomid hosts. Applied Entomology and Zoology, 31, 168-170.

Iwasa, Y. (1981) [Adaptive strategies of organisms: mathematical biology from a sociobiological viewpoint]. Saiensu-sha, Tokyo, Japan. [In Japanese]

Jallon, J.M. (1984) A few chemical words exchanged by Drosophila during courtship and mating. Behavior Genetics, 14, 441-478. 
King, P.E., Askew, R.R. \& Sanger, C. (1969) Detection of parasitised hosts by males of Nasonia vitripennis (Walker) (Hymenoptera - Pteromalidae) and some possible implications. Proceedings of the Royal Entomological Society of London. Series A, General Entomology, 44, 85-90.

Leal, W.S., Kuwahara, S., Shi, X.W. et al. (1998) Male-released sex pheromone of the stink bug Piezodorus hybneri. Journal of Chemical Ecology, 24, 1817-1829.

Loch, A.D. \& Walter, G.H. (1999) Does the mating system of Trissolcus basalis (Wollaston) (Hymenoptera:Scelionidae) allow outbreeding? Journal of Hymenoptera Research, 8, $238-250$.

Loch, A.D. \& Walter, G.H. (2002) Mating behavior of Trissolcus basalis (Wollaston) (Hymenoptera: Scelionidae): Potential for outbreeding in a predominantly inbreeding species. Journal of Insect Behavior, 15, 13-23.

McRobert, S.P. \& Tompkins, L. (1983) Courtship of young males is ubiquitous in Drosophila melanogaster. Behavior Genetics, 13, 517-523.

Maklakov, A.A. \& Bonduriansky, R. (2009) Sex differences in survival costs of homosexual and heterosexual interactions: evidence from a fly and a beetle. Animal Behaviour, 77, $1375-1379$.

Myint, W.W. \& Walter, G.H. (1990) Behaviour of Spalangia cameroni males and sex ratio theory. Oikos, 59, 163-174.

Nadel, H. \& Luck, R.F. (1992) Dispersal and mating structure of a parasitoid with a female-biased sex-ratio - implications for theory. Evolutionary Ecology, 6, 270-278.

Quicke, D.L.J. (1997) Parasitic Wasps. Chapman \& Hall, London, U.K.

R Core Team (2014) R: A language and environment for statistical computing. R Foundation for Statistical Computing, Vienna, Austria. http:// www.R-project.org/ 
Robacker, D.C., Weaver, K.M. \& Hendry, L.B. (1976) Sexual communication and associative learning in the parasitic wasp Itoplectis conquisitor (Say). Journal of Chemical Ecology, 2, 39-48.

Ruther, J. \& Steiner, S. (2008) Costs of female odour in males of the parasitic wasp Lariophagus distinguendus (Hymenoptera: Pteromalidae). Naturwissenschaften, 95, $547-552$.

Salerno, G., Frati, F., Iacovone, A. et al. (2012) A female-produced short-range sex pheromone in the egg parasitoid Trissolcus brochymenae. Invertebrate Biology, 131, 144-153.

Scharf, I. \& Martin, O.Y. (2013) Same-sex sexual behavior in insects and arachnids: prevalence, causes, and consequences. Behavioral Ecology and Sociobiology, 67, 1719-1730.

Schwartz, A. \& Gerling, D. (1974) Adult biology of Telenomus remus (Hymenoptera: Scelionidae) under laboratory conditions. Entomophaga, 19, 483-492.

Schwörer, U., Volk1, W. \& Hoffmann, K.H. (1999) Foraging for mates in the hyperparasitic wasp, Dendrocerus carpenteri: impact of unfavourable weather conditions and parasitoid age. Oecologia, 119, 73-80.

Sharkey, M.J. (2007) Phylogeny and classification of Hymenoptera. Zootaxa , 1668, 521-548.

Steiner, S., Steidle, J.L.M. \& Ruther, J. (2005) Female sex pheromone in immature insect males - a case of pre-emergence chemical mimicry? Behavioral Ecology and Sociobiology, 58, 111-120.

Stojković, B., Jovanović, D.Š., Tucić, B. \& Tucić, N. (2010) Homosexual behaviour and its longevity cost in females and males of the seed beetle Acanthoscelides obtectus. Physiological Entomology, 35, 308-316. 
Strand, M.R. (1988) Variable sex-ratio strategy of Telenomus heliothidis (Hymenoptera, Scelionidae) - adaptation to host and conspecific density. Oecologia, 77, 219-224.

Tagawa, J. \& Kitano, H. (1981) Mating behavior of the braconid wasp, Apantelesglomeratus L. (Hymenoptera, Braconidae) in the field. Applied Entomology and Zoology, 16, 345-350.

van den Assem, J., Gijswijt, M.J. \& Nubel, B.K. (1980) Observations on courtship strategies and mating strategies in a few species of parasitic wasps (Chalcidoidea). Netherlands Journal of Zoology, 30, 208-227.

van Welzen, C.R.L. \& Waage, J.K. (1987) Adaptive responses to local mate competition by the parasitoid, Telenomus remus. Behavioral Ecology and Sociobiology, 21, 359-365.

Waage, J.K. (1982) Sib-mating and sex-ratio strategies in scelionid wasps. Ecological Entomology, 7, 103-112.

Wilson, F. (1961) Adult reproductive behaviour in Asolcus basalis (Hymenoptera: Scelionidae). Australian Journal of Zoology, 9, 739-751. Zar, J.H. (2010) Biostatistical Analysis 5th ed. Pearson, London, U.K. 


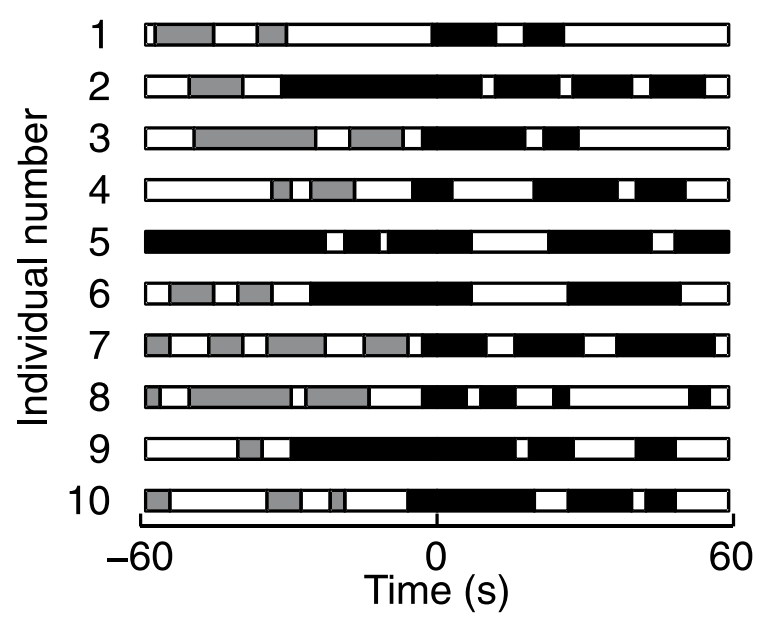

Fig. 1 Sexual behaviour of male adults of the parasitoid wasp Telenomus triptus toward other males emerging subsequently. The time when the body of a wasp is completely exposed as it exits from the host egg shell is defined as the emergence of the wasp ( 0 in the figure).

Successive emergence of two male wasps was observed, and the occurrences and duration of watching posture and mount were examined in the earlier emerging male for 1 min before and after the emergence of the subsequently emerging male. Watching posture (grey bars): a male wasp stops in front of another emerging individual and holds his antennae forward and slightly vibrates them. Mount (black bars): a male wasp climbs another individual bending his antennae in an arcing form and vibrating them vigorously. One of the first males (individual number 5) started to show watching posture $60-120 \mathrm{~s}$ before the emergence of the second male (not shown in the figure). 

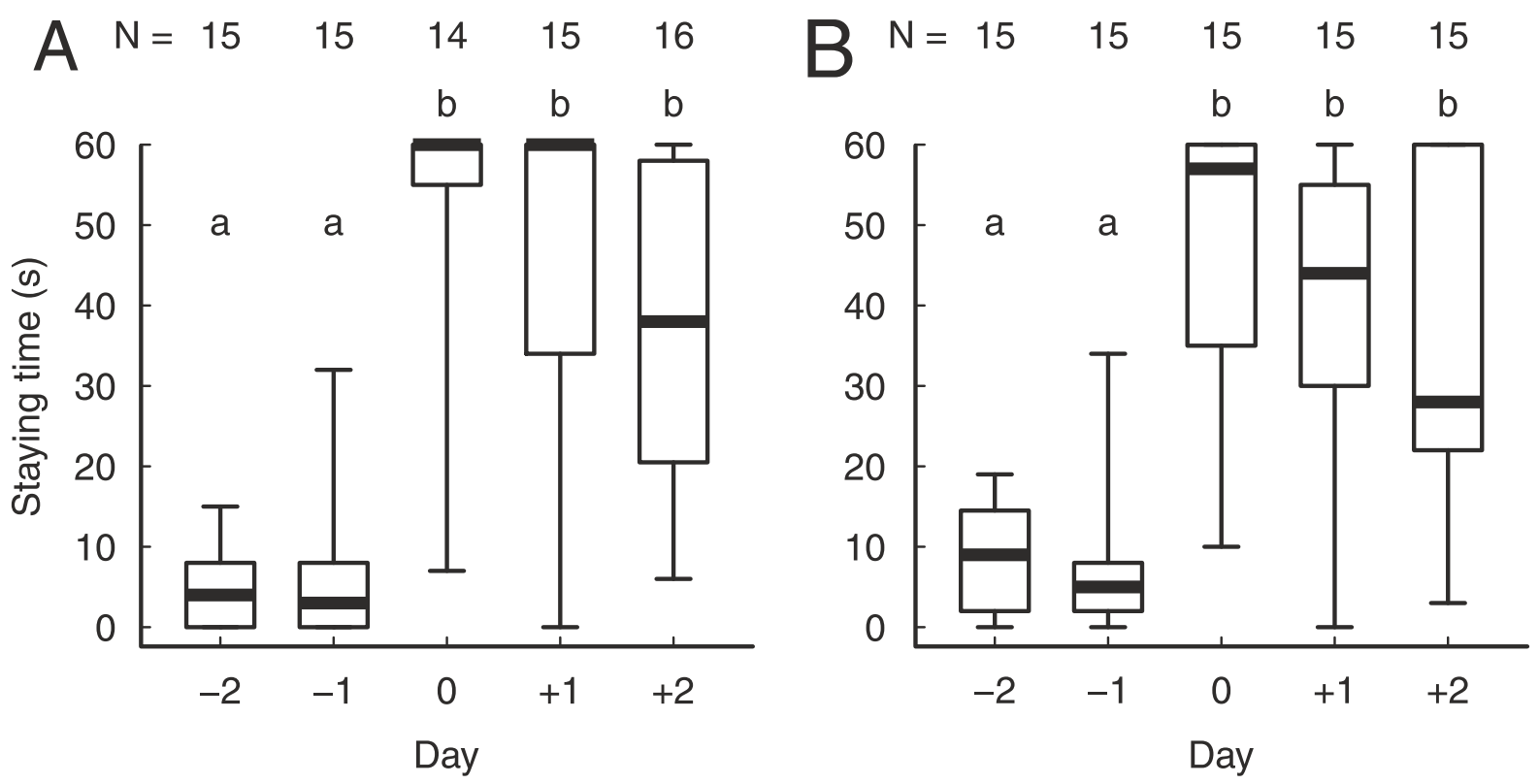

Fig. 2 Maximum staying time of male adults of Telenomus triptus on parasitized host egg masses with (A) both-sex or (B) only male wasps. The day when the first wasp emerged from a host egg mass was designated as day 0. Box-and-whisker plots with different letters in a panel are significantly different (Steel-Dwass test, $P<0.05$ ). Staying times longer than $60 \mathrm{~s}$ were taken as $60 \mathrm{~s}$. Bold lines in boxes indicate medians, and lower and upper borders of boxes indicate the first and third quartiles, respectively. Whiskers designate ranges. 


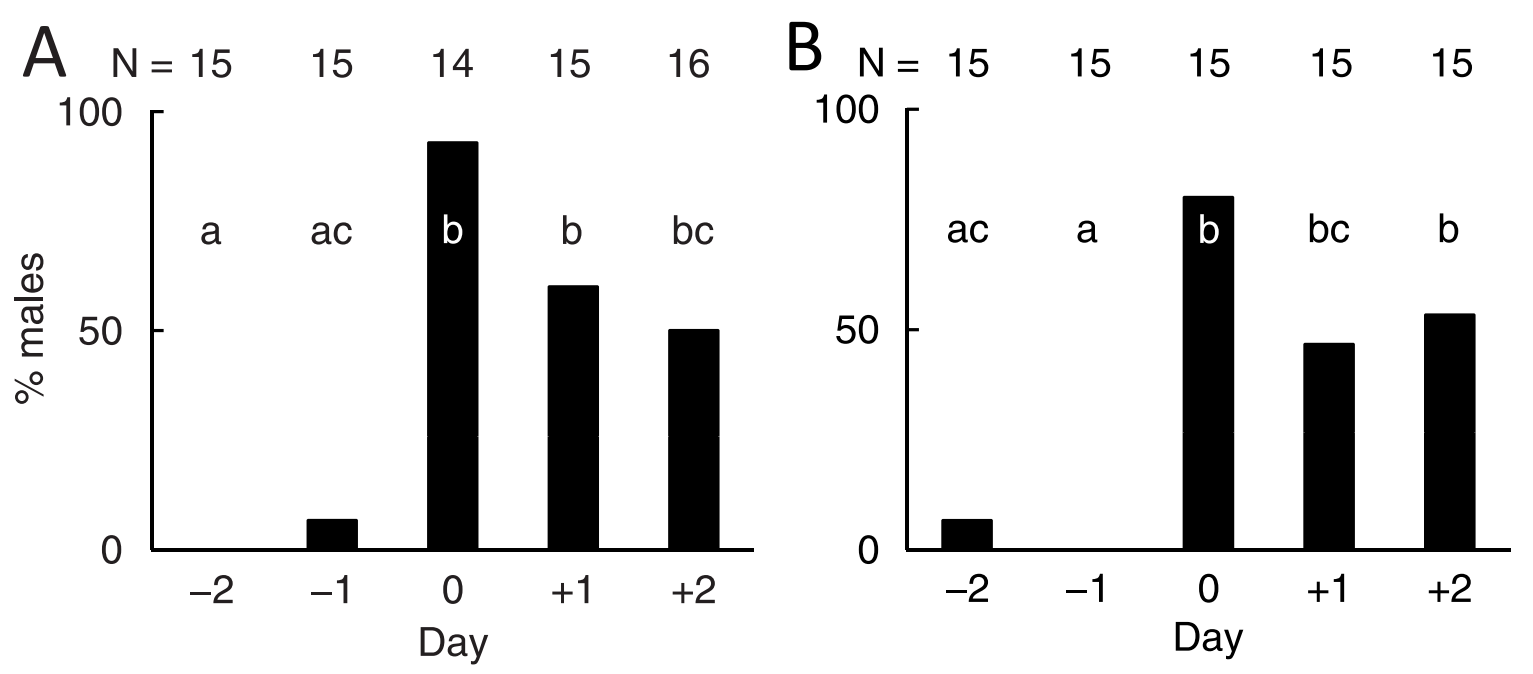

Fig. 3 Proportion of male adults of Telenomus triptus showing "watching posture" on parasitized host egg masses with (A) both-sex or (B) only male wasps. The day when the first wasp emerged from a host egg mass was designated as day 0. Proportions with different letters are significantly different (Tukey-type multiple comparisons for proportions, $P<0.05$ ). Watching posture: a male holds his antennae forward and slightly vibrates them on an egg mass. 


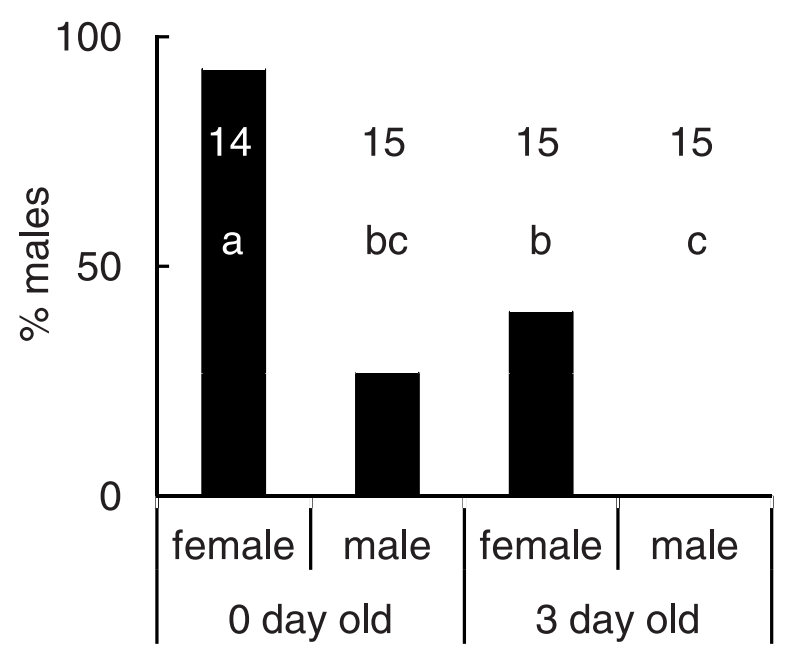

Fig. 4 Proportion of male adult Telenomus triptus showing "aedeagus extrusion" toward freshly killed conspecifics. Female or male, 0-day-old or 3-day-old wasps were killed and presented to a male adult. The male adults were used for experiments $0-3$ days after emergence. Numbers in the bars indicate the number of trials. Proportions with different letters are significantly different (Tukey-type multiple comparisons for proportions, $P<$ $0.05)$. 